\title{
When Outcomes Prompt Criticism of Procedures: An Analysis of the Rodney King Case
}

\author{
Elizabeth Mullen* \\ Kellogg School of Management, Northwestern University
}

\author{
Linda J. Skitka \\ Department of Psychology, University of Illinois at Chicago
}

A content analysis of newspaper editorials about the trial of the four officers accused of beating Rodney King investigated when people would become concerned with procedural propriety in the case. Consistent with research demonstrating that people's moral convictions are important determinants of their perceptions of fairness and reactions to outcomes, results revealed that people were more critical of the procedures used in the case after learning the "unjust" verdict than before. Specifically, editorials only mentioned aspects of procedures after the verdict was announced, despite potential reasons for preverdict procedural concern. Editorials also contained more mentions of racism post- than preverdict suggesting that the "unjust" verdict also prompted concerns with institutionalized procedural problems.

Rodney King was a Black motorist who was beaten and arrested by four White police officers in Los Angeles on March 3, 1991. An onlooker captured the beating on videotape from his apartment window and released it to the press. Based on widespread public dissemination of a cropped version of the videotape (that omitted Rodney King charging at the police officers), most Americans believed that the officers were guilty of using excessive force against King (see Cannon, 1999). When the police officers were acquitted of charges on April 30, 1992, riots broke out in Los Angeles that left 54 people dead, 2,000 injured, and more than 800 buildings burned (Cannon, 1999). Additionally, the handling of this case exacerbated

\footnotetext{
* Correspondence concerning this article should be addressed to Elizabeth Mullen, Kellogg School of Management, Northwestern University, Management and Organizations, 2001 Sheridan Road, Evanston, IL 60208 [e-mail: e-mullen@kellogg.northwestern.edu].
} 
tensions between the African American community and the Los Angeles police department.

The current study investigated when people become concerned about procedural propriety in these types of highly publicized cases and the implications of achieving a just or unjust verdict. Current theories of justice tell us a great deal about what people are likely to perceive as fair or unfair and the factors that influence people's perceptions of fairness, but tell us relatively little about when people become concerned about fairness. Many justice studies are one-shot encounters in the lab or cross-sectional surveys at one point in time where people are explicitly asked to make judgments of fairness. Consequently, these studies tell us little about when people spontaneously become concerned about fairness in the absence of being directly asked to provide a fairness judgment. Are people vigilant to aspects of procedures as they unfold in cases where they care deeply about obtaining a "just" outcome, or are people only concerned about procedures after learning the procedures failed to yield the "correct" outcome?

To gain insight into when people become concerned about whether procedures are fair (before or after outcomes are known), and how people react to "unjust" outcomes in these types of cases, we conducted a content analysis of newspaper editorials about the Rodney King case that were published before and after the verdict in the trial of the four police officers who were charged with beating King was announced. We drew on theories of procedural justice and recent theorizing on the moral mandate effect to inform predictions about when people would care about procedural fairness and how people would react to the verdict in the case.

\section{Procedural Fairness}

Considerable research on the fair process effect documents that fair procedures positively impact people's subsequent thoughts, feelings, and behaviors (e.g., Folger, Rosenfeld, Grove, \& Corkran, 1979). For example, positive aspects of procedures predict people's perceptions of procedural and distributive fairness, their satisfaction with procedures and outcomes, and their willingness to accept and comply with the decisions of authorities (e.g., Lind \& Tyler, 1988; Tyler, Casper, \& Fisher, 1989; Tyler \& Lind, 1992; see Tyler \& Smith, 1999 for a review). Considerable research has shown that people are more willing to accept negative, unfavorable, and nonpreferred outcomes when they are arrived at by institutional procedures that are perceived as fair (e.g., Greenberg, 1987; Greenberg \& Folger, 1983; Tyler, 1990; Van den Bos, Wilke, Lind, \& Vermunt, 1998). Structural and interactional aspects of procedures predict how people reason about fairness when they are the direct recipient and when they are a third party perceiver of procedural treatment (Van den Bos \& Lind, 2001).

Given the importance of procedural factors in shaping people's perceptions of fairness and their reactions to decisions, one could predict that people should 
be attentive to the procedural details of a highly publicized trial, such as the trial of the four officers accused of beating Rodney King, long before the verdict is announced and they should continue to emphasize procedural aspects in the case after the verdict is announced. That is, people should be vigilant to whether authorities are behaving in fair or unfair ways prior to and after learning the verdict in the case. More recent research on the moral mandate effect, however, suggests that procedural factors are of less concern than achieving the "right" outcome when people have strong moral convictions about the outcome of a case.

\section{Moral Mandates}

Moral mandates are defined as the attitude positions or stands that people develop out of a moral conviction that something is right or wrong, moral or immoral (Skitka, 2002; Skitka, Bauman, \& Sargis, 2005; Skitka \& Mullen, 2002). Moral mandates are theorized to be different from people's otherwise strong but nonmoral attitudes in a number of ways. First, moral beliefs are experienced as imperatives, rather than preferences about which reasonable people can disagree. For example, one can accept and be friends with someone who does not share one's passion for chocolate or opera; however, it is much more difficult to be friends with someone who does not share one's moral belief that spouse abuse is fundamentally wrong. Second, moral mandates are experienced as facts about the world much like "13 is a prime number." In contrast, people recognize that their strong but nonmoral preferences are subjective rather than objective. Finally, recent research has found that the social and interpersonal consequences of attitudes held with strong moral conviction cannot be explained simply by constructs such as attitude extremity, importance, certainty, or centrality (see Skitka et al., 2005 for more detail).

Recent research on the moral mandate effect has demonstrated that when people have a moral mandate about what constitutes a fair outcome, their sense of fairness is determined more by whether their mandated outcome is achieved than by procedural fairness (e.g., Skitka, 2002; Skitka \& Houston, 2001; Skitka \& Mullen, 2002). For example, participants in Skitka and Houston's (2001) study read about a defendant who was accused of murder. People's moral mandates about the outcome of the trial were created by manipulating the true guilt or innocence of the defendant. One third of the participants learned through insider information that the defendant was "truly guilty," one third learned that the defendant was "truly innocent," and one third learned that people close to the case were divided as to the true guilt or innocence of the defendant (i.e., the defendant's guilt was ambiguous). The procedural propriety of the trial was also manipulated. Although all participants learned that the defendant was put to death, half of the participants learned that the defendant was executed after receiving the death penalty following his trial, whereas the other half learned that the defendant was killed in an act of 
vigilante justice before having a trial. Results revealed that even in the case of an egregious procedural violation (when the defendant was killed in an act of vigilante justice) people's perceptions of procedural and outcome fairness were still shaped more by whether their mandated outcome was achieved (i.e., that the guilty were punished and the innocent set free) than by the fairness of the procedures. That is, people thought that putting a guilty man to death was fair and an innocent man to death unfair irrespective of the fairness of the procedures.

Similarly, Skitka and Mullen (2002) found that people's judgments of the fairness of the procedures and the outcome of the Elián González case were determined more by their moral mandates about the case (i.e., whether Elián should be returned to Cuba or be allowed to remain in the United States) than by their perceptions of procedural fairness. It is important to note that in each of these studies people's judgments of procedural fairness, and not only their judgments of outcome fairness, were determined by whether outcomes matched their morally preferred conclusions. What these studies did not address was how moral mandates influenced people's assessments of procedural fairness. Specifically, did people suspend judgment about whether a process was fair until after they learned whether it yielded the "correct" outcome? Or, were people motivated to actively revise already established judgments of procedural fairness when outcomes failed to match moral mandates?

Considerable research on motivated reasoning (e.g., Kunda, 1990) supports the notion that when outcomes fail to match people's moral mandates, people should be more likely to seek out problems with the procedures to support the conclusion that the procedures were unfair. For example, although people tend to be cognitive misers who rely on simple, low-effort heuristics under most circumstances (e.g., Fiske \& Taylor, 1991), people shift into a more thoughtful and analytical mode of reasoning when they experience something negative or unexpected (cf., Rutte \& Messick, 1995; Wong \& Weiner, 1981). People are more critical of information that is inconsistent with their prior beliefs relative to information that is consistent with their prior beliefs (e.g., Ditto \& Lopez, 1992; Edwards \& Smith, 1996; Houston \& Fazio, 1989; Klein \& Kunda, 1992, Kunda, 1987). For example, in Lord, Ross, and Lepper's (1979) classic study, people found much more fault with the procedures researchers used for collecting data when the results of the researchers' studies contradicted, rather than supported, their beliefs.

In sum, research on the moral mandate effect suggests that people should care more about obtaining the "correct" outcome in the trial of the officers accused of beating King, than the procedures used in the trial. One implication of the moral mandate effect is that people should interpret the trial procedures to be differentially fair as a function of whether the outcome of the trial supported or opposed their moral mandate. Accordingly, we predicted that people would be more critical of aspects of procedures after learning that the outcome failed to match their moral mandate than before. 
In addition to influencing how people perceive procedures and outcomes, moral mandate theorizing predicts that threats to one's moral mandates (in the form of an unjust verdict) should produce significant consequences (e.g., moral outrage, protest). Specifically, value protection theorists argue that people respond to challenges to their moral point of view with moral outrage and a desire to punish and derogate the transgressor (e.g., Skitka, 2002; Skitka \& Mullen, 2002; Tetlock, Kristel, Elson, Green, \& Lerner, 2000). When people think about or experience a transgression of a moral mandate by others, moral outrage will typically involve negative attributions about the transgressor(s) that in turn lead to a perception of injustice, anger, contempt, negative sanctions, and/or protest (Skitka \& Mullen, 2002). Thus, the moral mandate hypothesis also predicts that threats to one's moral mandate (e.g., the acquittal of the four officers accused of beating Rodney King) should lead people to engage in moral outrage (denigrating the institutions responsible for the "unjust" verdict).

\section{Summary of Hypotheses and Overview of the Current Study}

The trial of the four police officers accused of beating King and the riots that followed the verdict in the case aroused much public interest and attention. Given the extensive publicity and public concern over the case, the trial provided a unique opportunity to gain a greater understanding of how people reason about fairness, because (a) most people believed that the officers were guilty of using excessive force, ${ }^{1}$ and (b) there were several questionable procedural changes that occurred in the case prior to the verdict. That is, the change of venue from Los Angeles to the more affluent and Caucasian context of Simi Valley and the subsequent selection of an all-White jury, presented the possibility of significant preverdict procedural concern, because Rodney King was Black, but the four police officers charged with beating him were White.

If people are vigilant to procedural aspects of these types of highly publicized trials, and if procedural considerations tend to be the primary factor that shapes people's reactions to outcomes such as trial verdicts, then we should see a significant amount of preverdict concern with procedures in this case, and an equal degree of concern about procedures pre- and postverdict. If, however, observers are more critical of procedures after being confronted with outcomes that fail to match moral mandates (the moral mandate hypothesis), we should observe more procedural concern post- than preverdict. Additionally, the moral mandate

\footnotetext{
${ }^{1}$ Although moral mandate could not be directly measured, there is strong poll evidence that most people felt that the defendants in the Rodney King case were guilty of using excessive force (see Cannon, 1999 for details). Moreover, other research has established that people have a moral mandate that the guilty should be punished and the innocent set free (Skitka \& Houston, 2001, Study 1A). Therefore, it is reasonable to assume that most people had a moral mandate that the four officers should have been convicted of using excessive force.
} 
hypothesis predicts that the acquittal of the four officers accused of beating Rodney King should lead people to engage in moral outrage (derogating the authorities and institutions responsible for the "unjust" verdict). Thus, we should see more comments that are critical of authorities after than before the verdict. To test these hypotheses, we content coded and analyzed newspaper editorials and letters to the editor about the Rodney King case that were published before and after the verdict was announced.

\section{Method}

Eighty editorials and letters to the editor about Rodney King were identified using the LexisNexis database. The search was limited to the top 20 major daily newspapers in the United States using Lexis criteria and was further limited to editorial page content using the command, "subject heading = editorial."2 This strategy captured newspaper editorials written by each newspaper's editorial staff, columnists' essays printed on the editorial pages, as well as letters to the editor. Finally, the database was searched using the keyword "Rodney King." Two separate time periods were searched. The preverdict time period, from March 15, 1991 (when the four officers accused of beating Rodney King were indicted) to April 29, 1992, yielded 75 editorials from 15 different newspapers. We chose the indictment of the officers as the beginning of the preverdict time period because it marked the beginning of the legal proceedings. The postverdict time period, from April 30, 1992 (when the verdict was announced) to May 29, 1992 (one month later), yielded 385 editorials from 12 different papers. Forty editorials were randomly selected from each time period for analysis. Twenty-eight percent of the preverdict editorials and $35 \%$ of the postverdict editorials were letters to the editor, the remaining editorials were columnists' essays printed on the editorial pages or editorials written by staff writers.

Two independent coders content coded every third grammatical sentence in the editorials as reflecting something about (a) outcomes (e.g., references to defendant guilt, the verdict, or verdict preference if preverdict), (b) procedures (e.g., mentions of the jury, change of venue, judge instructions, whether King should have testified), (c) police brutality (e.g., general comments about police brutality), (d) explicit criticism of the police (e.g., criticism of Chief Gates, handling of riots), (e) racism (e.g., institutional racism), (f) riots (e.g., riots are appalling),

\footnotetext{
${ }^{2}$ There was at least one editorial or letter to the editor in the pre- and postverdict time periods from the following papers: The Washington Post, St. Louis Post, Boston Globe, Chicago Tribune, Philadelphia Inquirer, San Francisco Chronicle, Denver Rocky Mountain News, Miami Herald, The Oregonian, Atlanta Journal and Constitution, Christian Science Monitor, and the Los Angeles Times. Additionally, preverdict editorials also appeared in the Seattle Times, St. Petersburg Times and the New York Times.
} 
or (g) other types of comments (e.g., politics). ${ }^{3}$ For efficiency, only every third sentence in the editorials was coded. The two coders agreed on $88 \%$ of the codes overall and discrepancies were resolved through discussion until consensus was reached. Specifically, the percentage agreement within response categories ranged from $83 \%$ for the police brutality category to $95 \%$ for the criticism of police category, indicating that agreement was comparably high across categories. Finally, analyses revealed that there were no differences in the frequency of the different types of comments as a function of whether the article was a letter to the editor or an editorial written by a staff writer or columnist, $\chi^{2}(6, N=575)=3.11, p=$ .79 ; therefore this variable was not included in further analyses.

\section{Results}

The moral mandate hypothesis predicted that people would be more critical of and more likely to comment on the procedures in the case after learning the verdict than before (because the verdict was inconsistent with their moral mandate). Furthermore, the moral mandate hypothesis predicted that people would respond to threats to their moral mandates by criticizing institutions responsible for the "unjust" verdict (a component of moral outrage).

To test these hypotheses, chi-squares were conducted that analyzed how many mentions of each of the coding categories occurred as a function of time (pre- or postverdict). Comments about the riots were excluded from these chi-square analyses because they could only occur postverdict, but they are included in Table 1 for descriptive purposes. Results of these chi-square analyses are reported in Table 1 and are described below. Overall, results revealed that there were significant differences in the types of comments that occurred before and after the verdict, $\chi^{2}(5, N=538)=109.35, p<.001$.

\section{Procedural Fairness}

Supporting the moral mandate hypothesis, results revealed that there was not a single mention of the procedures used in the case preverdict. Rather, all of the procedural comments occurred after the verdict was announced. Thus, people were more likely to comment on and be critical of aspects of the procedures used in the case after learning the verdict than before.

\footnotetext{
${ }^{3}$ Note that comments about the riots could only have occurred post-verdict because the riots happened after the verdict was announced. Therefore, this coding category was only utilized for the post-verdict editorials. All other coding categories could have occurred pre- or post-verdict and thus were utilized for both sets of editorials.
} 
Table 1. Percentage of Rodney King Editorial Page Comments Pre- and Postverdict ( $n$ in parentheses)

\begin{tabular}{lcc}
\hline Comment & $\begin{array}{c}\text { Preverdict } \\
(n=284)\end{array}$ & $\begin{array}{c}\text { Postverdict } \\
(n=291)\end{array}$ \\
\hline Procedures & $0 \%(0)$ & $100 \%(27)$ \\
Outcome & $0 \%(0)$ & $100 \%(24)$ \\
Riots & $0 \%(0)$ & $100 \%(37)$ \\
Racism & $21.4 \%(6)$ & $78.6 \%(22)$ \\
Criticism of police & $75.0 \%(45)$ & $25.0 \%(15)$ \\
Police brutality & $88.5 \%(69)$ & $11.5 \%(9)$ \\
Other & $51.1 \%(164)$ & $48.9 \%(157)$ \\
\hline
\end{tabular}

$\chi^{2}(5, N=538)=109.35, p<.001$.

Note. Comments about the riots were excluded from the chi-square analysis because they could only occur post-verdict, but are included in the table for descriptive purposes.

\section{Police Brutality and Criticism of the Police}

Many of the editorial comments also focused on problems with the police. Although editorials and letters to the editor mentioned police brutality pre- and postverdict, these comments were more frequent before than after the verdict. Similarly, editorial writers and people who wrote letters to the editor criticized the police (e.g., explicitly criticized Los Angeles Police Chief Darryl Gates) pre- and postverdict, but these comments were more frequent pre- than postverdict . Thus, preverdict editorials were largely focused on criticizing the police and problems with police brutality and were not focused on procedural aspects of the legal case.

\section{Comments About Racism, the Riots, and the Outcome}

Not surprisingly, all of the comments about the riots and the verdict occurred in the postverdict editorials. However, the majority of the comments about racism (78.6\%) also occurred after the verdict was announced, suggesting that the verdict also triggered thoughts of larger problems with institutional racism.

\section{Discussion}

The moral mandate hypothesis predicted that there would be more concern with aspects of the procedures after the public learned that the verdict failed to support their morally mandated outcome than before they learned about the verdict. Results supported the moral mandate hypothesis: Specifically, editorials and letters to the editors only included comments about aspects of the procedures after learning the verdict. There was not one mention of procedural impropriety before the verdict was announced, despite the fact that the change of venue and all-White jury allowed 
for ample concern with the procedures prior to the verdict (and these specific procedural concerns were certainly raised after the verdict). It seems that the perceived unfairness of the verdict prompted concerns about the procedural details of the case. One could argue, given the lack of preverdict procedural concern, that had the "right" verdict in the case been reached (i.e., that the officers were convicted of using excessive force), that editorial writers and the public may have been willing to overlook the questionable procedural details, because justice would have been served. That is, in the absence of the unfair verdict, procedural elements of the case may not have been mentioned in the editorial pages at all.

In addition to the results that indicated that editorial writers and those who write letters to the editor (and perhaps, therefore, also the general public) were more concerned about procedural fairness after rather than before learning the trial verdict, other results revealed that editorials and letters to the editor were much more likely to also focus on racism and problems with institutionalized racism after the verdict was announced than before. This result suggests that failing to obtain one's mandated outcome leads people to criticize not only the procedures used in the specific case but also leads people to question the fairness of the decision-making procedures and institutions more generally (see also Skitka, 2002). Moreover, the focus on racism in conjunction with the widespread rioting that occurred after the verdict was announced provides support for the moral outrage component of the moral mandate hypothesis.

Finally, other results revealed that preverdict editorials and letters to the editor focused on problems with police brutality and criticism of the police (e.g., criticism of Police Chief Gates). These results are not surprising given the salience of police brutality at the time due to the widespread dissemination of the videotape that portrayed King being beaten by the four police officers.

The results of this content analysis inform research and theories about how people reason about fairness. Recent research on the moral mandate effect suggests that when people have moral mandates about what constitutes a "fair" outcome, achieving that outcome is more important than procedural propriety in shaping their perceptions of fairness and decision acceptance. The current work extends this previous work by demonstrating that people were relatively unconcerned about the fairness of the procedures until after learning that those procedures failed to produce the "right" outcome. Certainly, in this context, where most people had a strong preconceived notion about what the "fair" outcome should be, there was clear evidence in editorial page content of a public outcry about the perceived injustice of the verdict and deep concern about the fairness of the procedures and the system that could have produced such a verdict. This is not to say that fair procedures are not important; a considerable amount of research documents the positive aspects of fair procedures (Lind \& Tyler, 1988). Rather, these results suggest that in contexts where people have a clear sense of what the fair outcome is, those aspects of procedures matter much less in shaping people's outcome or 
procedural fairness judgments (see also Skitka \& Houston, 2001; Skitka \& Mullen, 2002). This interpretation is also consistent with the notion that the fair process effect is much weaker when people have clear outcome information (e.g., social comparison information) relative to when they lack such outcome information (Van den Bos, Lind, Vermunt, \& Wilke, 1997; Van den Bos et al., 1998).

The current study has a number of methodological virtues. Specifically, by using an archival method, we were able to capture pre- and post-reactions to a particularly controversial verdict. Reactions to the court case were sampled from across the United States, and these reactions were in response to a very real and vivid event. Most justice research studies are either one-shot encounters in the lab, or involve data collection (including retrospective reports) at only one period of time. However, justice is likely to emerge as a relevant concern in situations that are anything but one-shot, and it is well known that what people retrospectively report feeling or thinking has only a small correspondence with what they may have actually been feeling or thinking during the situation (e.g., Nisbett \& Wilson, 1977). Because of a lack of longitudinal research that has explored people's justice reasoning as it emerges over time, we have relatively limited understanding of justice reasoning as an emergent process. One of the virtues of the present study's approach to exploring justice reasoning was that observations were collected over a period of time, allowing for a stronger assessment of when, for example, people became concerned about procedural propriety. It would have been easy for people to retrospectively report that they had been deeply concerned about the change of venue or the all-White jury if they had been asked about it postverdict. However, because we coded what people thought was important enough to mention in the commentary about the King case both before and after the verdict, it was possible to disentangle when people spontaneously became concerned about procedural details - before or after they learned that the verdict was one that they disagreed with. In sum, by exploring reactions to the King case over time, we were able to clearly ascertain that the outcome of the trial drove people's concerns about procedures.

Despite these strengths, our methodological approach also had a number of limitations. For example, people who write letters to the editor of their local newspaper, or who otherwise contribute to the editorial pages, may not be particularly representative of people at large. In addition, we were left to assume that people had a moral mandate about the verdict in this case, but we were not able to directly measure whether this was in fact the case. However, in conjunction with the research conducted in the lab and in natural experiments, these results take on greater credibility. The moral mandate hypothesis has now received support when tested with controlled laboratory experiments (Skitka \& Houston, 2001), national field studies (Skitka \& Mullen, 2002), as well as with the present archival analysis.

That said, there is considerable room for additional research. For example, we still have limited understanding of the underlying processes that might lead to the 
moral mandate effect. Why do people tend to care more about outcomes than procedures in contexts like the Rodney King case? Although the results of the present study provided novel evidence that people are more likely to derogate aspects of procedural fairness after learning that outcomes fail to match moral mandates, they do not conclusively establish the mechanism that accounts for this effect. Were people in fact motivated to engage in more extensive information processing about procedural elements of the case after learning that their mandated outcome was not supported? Would people have been willing to accept the questionable aspects of the change of venue had the "right" outcome been reached? Moreover, given that the Rodney King verdict aroused people's emotions (e.g., anger) to a strong degree, one alternative explanation for the influence of moral mandates on people's perceptions of fairness is that people's emotional reactions drive their perceptions of fairness. People sometimes judge moral and immoral, right and wrong, on the basis of visceral and intuitive, rather than deliberative, cognitive processes (Haidt, 2001). Perhaps, people's anger at the verdict shaped their reactions to the case in general and their criticism of the procedures in the case without motivating them to more carefully scrutinize the procedural information. Future research should continue to explore the underlying motivational explanations for why people are more critical of procedures after learning that their mandated outcome was not supported.

Although there is considerable room for additional inquiry, exploring preand postverdict reactions to the Rodney King case advances our understanding of how people reason about fairness in important ways. Specifically, the current research provided novel evidence that people were more critical of procedures after learning that those procedures failed to yield the "just" outcome than they were before they knew the outcome, suggesting that procedural information is sometimes interpreted to be consistent with people's outcome preferences.

In addition to advancing our understanding of justice reasoning, the results of this content analysis also have important implications for public policy. For example, our results suggest that outcomes that violate people's moral mandates may influence not only their perceptions of that particular outcome, but also their level of support for and the perceived legitimacy of legal institutions more generally. Specifically, our results demonstrated that people were more likely to criticize aspects of procedures and talk about larger institutionalized procedural problems such as racism after learning that the verdict violated their notion of a "just" outcome. Additionally, other evidence documented that the verdict produced additional components of moral outrage (e.g., rioting and exacerbated tensions between the African American community and the Los Angeles police department; Cannon, 1999). The rioting and other strong reactions people had in response to this seemingly unfair verdict suggest that outcomes that fail to match moral mandates might lead people to be less willing to obey the law more generally. For example, Nadler (2005) found that participants who were exposed to laws they perceived as 
unjust reported they would be more willing to disobey unrelated laws (e.g., traffic violations, petty theft) than participants exposed to laws they perceived to be just. Taken together, these results suggest that outcomes that fail to support moral standards may (a) lead people to be less willing to obey the law more generally, and (b) degrade people's support for and deference to legitimate authorities. Governments depend on mass support of their political institutions and authorities. Decisions that fail to support the public's morally mandated outcomes may therefore erode support for the system as a whole, a finding that has serious implications and that deserves further exploration in future research.

On a more positive note, some have resisted the core policy implication of the procedural justice program of research (i.e., to design procedures so that they will be seen as maximally fair) because malevolent authorities could use artfully designed procedures to manipulate people into accepting unfair outcomes (Haney, 1991). One implication of the moral mandate line of work is that when people have moral mandates about outcomes, the appearance or even the reality of fair procedures does little to influence their willingness to accept anything less than what they see as right and to reject what is wrong. In short, people may not be as easily mollified by auspices of procedural fairness as Haney (1991) and others have feared, and authorities, policy makers, and others need to attend to ensuring that people receive procedural and outcome justice.

Taken together, the positive and negative implications of our research on moral mandates suggest that one needs to take a balanced approach when designing interventions to help allay the negative consequences associated with violations of moral mandates. For example, our work suggests that government officials need to design an effective strategy to communicate outcomes that are inconsistent with people's moral standards in such a way as to preserve people's support for the institution more broadly, even if they disagree with the particular outcome. Perhaps reminding people of the overarching goals of our justice system to both ensure that the right outcome is obtained and to protect the rights of defendants to receive due process might help to alleviate some of the moral outrage that people experience after learning about outcomes that violate their moral standards. At present, we do not know enough about what leads people to see some issues in morally mandated terms, and why people seemingly seldom place equal weight on due process as a moral priority in these types of cases. Perhaps the tendency for people to have a moral mandate about what constitutes a "fair" outcome in these types of cases is a consequence of an increasing tendency to try defendants in the popular press, which may in turn lead people to a priori judge defendant guilt or innocence. If the media could frame its messages by placing more equal emphasis on the importance of both distributive justice (achieving the "right" outcome) and procedural justice (protecting the defendant's right to due process), perhaps reactions like the LA riots could be avoided. 
Alternatively, one could argue that it is occasionally healthy for people to question authority and to reevaluate a system that produces seemingly unfair outcomes. Questioning the validity of the legal system does not have to lead to negative consequences; it could also inspire positive social change or lead people to reaffirm their commitment to the system if a suitable alternative cannot be identified. Thus, another challenge for future research will be to determine how to motivate people to harness the sense of injustice they feel when outcomes violate moral standards into positive behaviors designed to facilitate social change rather than destructive behaviors such as the rioting that occurred after the verdict in the trial of the four officers accused of beating King.

\section{References}

Cannon, L. (1999). Official negligence: How Rodney King and the riots changed Los Angeles and the $L A P D$. Boulder, CO: Westview Press.

Ditto, P. H., \& Lopez, D. F. (1992). Motivated skepticism: Use of differential decision criteria for preferred and nonpreferred conclusions. Journal of Personality and Social Psychology, 63, $568-584$.

Edwards, K., \& Smith, E. E. (1996). A disconfirmation bias in the evaluation of arguments. Journal of Personality and Social Psychology, 71, 5-24.

Fiske, S. T., \& Taylor, S. E. (1991). Social cognition, (2nd ed.). New York: McGraw-Hill.

Folger, R., Rosenfeld, D., Grove, J., \& Cockran, L. (1979). Effects of "voice” and peer opinions on responses to inequity. Journal of Personality and Social Psychology, 37, 2253-2261.

Greenberg, J. (1987). Reactions to procedural injustice in payment distributions: Do the means justify the ends? Journal of Applied Psychology, 72, 55-61.

Greenberg, J., \& Folger, R. (1983). Procedural justice, participation, and the fair process effect in groups and organizations. In P. B. Paulus (Ed.), Basic group processes (pp. 235-256). New York: Springer-Verlag.

Haney, C. (1991). The fourteenth amendment and symbolic legality: Let them eat due process. Law and Human Behavior, 15, 183-204.

Haidt, J. (2001). The emotional dog and its rational tail: A social intuitionist approach to moral judgment. Psychological Review, 108, 814-834.

Houston, D., \& Fazio, R. (1989). Biased processing as a function of attitude accessibility: Making objective judgments subjectively. Social Cognition, 7, 51-66.

Klein, W., \& Kunda, Z. (1992). Motivated person perception: Constructing justifications for desired beliefs. Journal of Experimental Social Psychology, 28, 145-168.

Kunda, Z. (1987). Motivated inference: Self serving generation and evaluation of causal theories. Journal of Personality and Social Psychology, 53, 636-647.

Kunda, Z. (1990). The case for motivated reasoning. Psychological Bulletin, 108, 480-498.

Lind, E. A., \& Tyler, T. R. (1988). The social psychology of procedural justice. New York: Plenum.

Lord, C. G., Ross, L., \& Lepper, M. R. (1979). Biased assimilation and attitude polarization: The effects of prior theories on subsequently considered evidence. Journal of Personality and Social Psychology, 37, 2098-2109.

Nadler, J. (2005). Flouting the law. Texas Law Review, 83, 1399-1441.

Nisbett, R. E., \& Wilson, T. D. (1977). Telling more than we can know: Verbal reports on mental processes. Psychological Review, 84, 231-259.

Rutte, C. G., \& Messick, D. M. (1995). An integrated model of perceived unfairness in organizations. Social Justice Research, 8, 239-261.

Skitka, L. J. (2002). Do the means justify the ends, or do the ends justify the means? A test of the value protection model of justice. Personality and Social Psychology Bulletin, 28, 588-597. 
Skitka, L. J., Bauman, C. W., \& Sargis, E. (2005). Moral conviction: Another contributor to attitude strength or something more? Journal of Personality and Social Psychology, 88, 895-917.

Skitka, L. J., \& Houston, D. A. (2001). When due process is of no consequence: Moral mandates and presumed defendant guilt or innocence. Social Justice Research, 14, 305-326.

Skitka, L. J., \& Mullen, E. (2002). Understanding judgments of fairness in a real-world political context: A test of the value protection model of justice reasoning. Personality and Social Psychology Bulletin, 28, 1419-1429.

Tetlock, P. E., Kristel, O. V., Elson, S. B., Green, M. C., \& Lerner, J. S. (2000). The psychology of the unthinkable: Taboo trade-offs, forbidden base rates, and heretical counterfactuals. Journal of Personality and Social Psychology, 78, 853-870.

Tyler, T. R. (1990). Why do people obey the law? Procedural justice, legitimacy, and compliance. New Haven, CT: Yale University Press.

Tyler, T. R., \& Lind, E. A. (1992). A relational model of authority in groups. In M. Zanna (Ed.), Advances in experimental social psychology (Vol. 4, pp. 595-629). New York: McGraw-Hill.

Tyler, T. R., \& Smith, H. J. (1999). Justice, social identity, and group processes. In T. R. Tyler \& R. M. Kramer (Eds.), The psychology of the social self. Applied social research (pp. 223-264). Mahwah, NJ: Erlbaum.

Tyler, T. R., Casper, J. D., \& Fisher, B. (1989). Maintaining allegiance toward political authorities: The role of prior attitudes and the use of fair procedures. American Journal of Political Science, 33, 629-652.

Van den Bos, K., \& Lind, E. A. (2001). The psychology of own versus others' treatment: Self-oriented and other-oriented effects on perceptions of procedural fairness. Personality and Social Psychology Bulletin, 27, 1324-1333.

Van den Bos, K., Lind, E. A., Vermunt, R., \& Wilke, H. A. M. (1997). How do I judge my outcome when I do not know the outcome of others? The psychology of the fair process effect. Journal of Personality and Social Psychology, 72, 1034-1046.

Van den Bos, K., Wilke, H. A. M., Lind, E. A., \& Vermunt, R. (1998). Evaluating outcomes by means of the fair process effect: Evidence for different processes in fairness and satisfaction judgments. Journal of Personality and Social Psychology, 74, 1493-1503.

Wong, P. T., \& Weiner, B. (1981). When people ask "why" questions, and the heuristics of attributional search. Journal of Personality and Social Psychology, 40, 650-663.

ELIZABETH MULLEN is a post-doctoral fellow at the Dispute Resolution Research Center at Northwestern University. Her research interests include social justice and political psychology. Her current work focuses on how people's emotions and moral convictions influence their fairness reasoning and judgments.

LINDA J. SKITKA is a professor at the University of Illinois at Chicago. Her current research interests include understanding the psychology of justice reasoning, moral conviction, and the cognitive and motivational underpinnings of the left-right political divide. She serves on the editorial boards of the Journal of Personality of Social Psychology, Journal of Experimental Social Psychology, Basic and Applied Social Psychology, and Social Justice Research and is president-elect of the International Society for Justice Research (see http://www.isjr.org for more information about ISJR). 